\title{
Trivalent Chromium Sorption on Alginate Beads
}

\author{
M. Manuela Araújo \& J. A. Teixeira \\ Departamento de Engenharia Biológica, Universidade do Minho Campus de Gualtar 4709 Braga, Codex - Portugal
}

(Received 30 September 1996; revised version received 26 May 1997; accepted 26 May 1997)

\begin{abstract}
The applicability of trivalent chromium removal from aqueous solutions using calcium alginate beads was studied. The equilibrium isotherms were plotted at two temperatures. The relationship between the chromium sorbed and the calcium released was determined as well as the effect of alginate amount and initial $\mathrm{pH}$ on the equilibrium results. Chromium sorption kinetics were evaluated as a function of chromium initial concentration and temperature. Transport properties of trivalent chromium on alginate beads were characterised by calculating chromium diffusion coefficients-the Linear Absorption Model and the Shrinking Core Model were assayed. Trivalent chromium removal from aqueous solutions, that made chromium alginate beads by directly dispensing the sodium alginate solution on chromium solutions, was also tested. Finally, a methodology for trivalent chromium removal with alginate is proposed. This method includes two steps: in the first, chromium is removed by using it as an agent for alginate bead formation (for chromium concentrations above $400 \mathrm{mgl}^{-1}$ ); afterwards, the obtained solution is placed in contact with previously formed alginate beads for removal of the remaining chromium. (C) 1997 Elsevier Science Ltd. All rights reserved
\end{abstract}

\footnotetext{
Nomenclature

$\alpha$

Ratio between the amount of solute in the solution and in the spheres, at equilibrium, dimensionless

Parameter of Eq. (8), order of the reaction, dimensionless

$\mathrm{C}$ Concentration of solute in the liquid phase, at equilibrium, $\mathrm{mmol}^{-1}$

$\mathrm{r}^{2}$

$\mathrm{C}^{0}$

$\mathrm{C}_{\mathrm{b}}$

$\mathrm{C}_{\mathrm{L} \infty}$

$\mathrm{C}_{\mathrm{L}}, \mathrm{C}_{\mathrm{L}}(\mathrm{t})$

$\mathrm{C}_{\mathrm{L} 0}, \mathrm{C}$

$\mathrm{D}_{\mathrm{e}}$

$\mathrm{D}_{\mathrm{e}}(\mathrm{LAM})$

$\mathrm{D}_{\mathrm{e}}(\mathrm{SCM})$ Correlation coefficient, dimensionless

Average binding site density, $\mathrm{mmoll}^{-1}$ of alginate Concentration of free solute inside the sphere, $\mathrm{mmoll}^{-1}$ of spheres

Concentration of solute in the solution at equilibrium, $\mathrm{mmoll}^{-1}$

Concentration of solute in the solution, $\mathrm{mmoll}^{-1}$

Initial concentration of solute in the solution, $\mathrm{mmoll}^{-1}$

Effective diffusion coefficient of the solute in the solid phase, $\mathrm{m}^{2} \mathrm{~s}^{-1}$

Diffusion coefficient calculated by LAM, $\mathrm{m}^{2} \mathrm{~s}^{-1}$

Diffusion coefficient calculated by $\mathrm{SCM}, \mathrm{m}^{2} \mathrm{~s}^{-1}$
}

$\mathrm{F}(\mathrm{X})$

k
$\mathrm{E}_{\mathrm{a}}$

K

$\mathbf{K}_{\mathbf{p}}$

Activation energy, $\mathrm{J} \mathrm{mol}^{-1}$

Function of $X$, defined by Eq. (7), dimensionless

Parameter of Eq. (8), $\mathrm{mol}^{1-\mathrm{a}} \mathrm{m}^{3 \mathrm{a}-3} \mathrm{~s}^{-1}$

Equilibrium ratio between the concentration of solute immobilised and the concentration of free solute, inside the solid phase, dimensionless

Partition coefficient of solute between the solid phase (spheres) and the liquid phase, at equilibrium, dimensionless

LAM Linear absorption model

Mca Amount of calcium released from the alginate beads at equilibrium, mmol Ca g ${ }^{-1}$ beads

n

Number of alginate beads in the reactor

q Amount of solute sorbed until equilibrium per unit of mass of adsorbent, $\mathrm{mmol} \mathrm{g}^{-1}$

$\mathrm{q}_{\mathrm{n}}$ Positive roots of Eq. (2), dimensionless

Radial coordinate of the sphere, $m$ 
64

\begin{tabular}{|c|c|}
\hline $\mathbf{R}$ & Sphere radius, $\mathrm{m}$ \\
\hline $\mathbf{R}$ & $\begin{array}{l}\text { Perfect gases constant, } \mathrm{J} \mathrm{mol}^{-1} \mathrm{~K}^{-1} \\
(8.314)\end{array}$ \\
\hline$r_{c}$ & $\begin{array}{l}\text { Radius of unchelated core inside the } \\
\text { particle, } m\end{array}$ \\
\hline SCM & Shrinking core model \\
\hline $\mathrm{t}$ & $\begin{array}{l}\text { Time, } s \text { (or minutes, if referred), } \\
\text { Temperature, } \mathrm{K} \text { (or }{ }^{\circ} \mathrm{C} \text {, if referred) }\end{array}$ \\
\hline V & Volume of solution, litre (l) \\
\hline $\mathrm{X}, \mathrm{X}(\mathrm{t})$ & $\begin{array}{l}\text { Ratio between the amount of solute } \\
\text { at solid phase at time } t \text { and at } \\
\text { equilibrium, defined by Eq. ( } 7 \text {, } \\
\text { dimensionless }\end{array}$ \\
\hline
\end{tabular}

\section{INTRODUCTION}

Due to the toxicity and commercial value of heavy metals, it has become increasingly urgent to develop new technologies for its removal from industrial effluents, and its reuse. The conventional physicochemical methods used for this purpose, such as chemical precipitation, elcctrowinnig, membrane separations, evaporation or resin ionic exchange, can be very expensive, and sometimes not very effective. The biological treatments, based on living microorganisms or plants, could be an alternative method to clean-up industrial wastewaters containing heavy metals. However, these processes are very sensitive to the characteristics of the effluent, as temperature, $\mathrm{pH}$ and chemical composition are not suitable for wastewaters with high metal concentrations.

The use of dead biomass and biomass derivatives (biossorbent materials) to remove heavy metals from aqueous solutions, has been widely studied in recent years (Volesky, 1987; Holan et al., 1993; Brady \& Tobin, 1994; Kratochvil et al., 1995; etc.). These systems are less expensive than the traditional physicochemical processes. They do not need nutrients and are resistant to the physical-chemical properties of heavy metal solutions.

Alginate, an exopolymer extracted mainly from brown seaweeds, has been used for a long time in several industrial applications. Among recent applications, alginate has been used as a cell immobilisation material (Martinsen et al., 1992) and as a biossorbent material to remove divalent heavy metals, such as $\mathrm{Cu}^{2+}, \mathrm{Co}^{2+}, \mathrm{UO}_{2}{ }^{2+}$ and $\mathrm{Zn}^{2+}$ from aqueous solutions. Alginate showed good metal sorption efficiency (Jang et al., 1991; Apel \& Torma, 1993; Chen et al., 1993; Lewandowski \& Roe, 1994).
Alginates are salts of unbranched copolymers, with $1 \rightarrow 4$ links, of $\beta$-D-mannuronic and $\alpha$-Lguluronic acids (Smidsrød \& Skjåk-Brœk, 1990). They produce thermally irreversible gels by association with most divalent cations.

Trivalent chromium is widely used in tanning industries and electrodeposition processes that generate high volumes of effluents at high chromium concentrations. Although trivalent chromium is not particularly toxic, its disposal as liquid effluents in natural waters or as sludges in soils, has to be avoided and controlled, for it may be oxidized, especially in soils, to the hexavalent form, which is highly toxic an carcinogenic.

The aim of this work is to develop a method to remove trivalent chromium from liquid effluents using alginate beads as sorption material. Characterisation of sorption mechanisms as well as transport properties will be studied.

\section{MATERIALS AND METHODS}

\section{Chemicals}

Sodium alginate (Manutex, RSX, Kelco Co.) was purchased from Sarcol Porto, Portugal). All the other chemicals were analytical grade.

\section{Experimental}

\section{Bead preparation}

Calcium alginate beads were prepared by dropping a $3 \%(w / v)$ sodium alginate aqueous solution on a stirred $2 \%(\mathrm{w} / \mathrm{v})$ calcium chloride solution. The beads were stirred in the $\mathrm{CaCl}_{2}$ solution for 24 hours. They were then washed three times with distilled water and maintained in a $2 \% \mathrm{CaCl}_{2}$ solution at $4^{\circ} \mathrm{C}$.

Immediately before use, the calcium alginate beads were washed again three times with distilled water and the excess water was absorbed on filter paper.

The mean diameter $(2.58 \mathrm{~mm})$ of beads was determined in a sample of 50 alginate beads using a micrometer. The mean weight $(9.30 \mathrm{mg})$ of the beads was determined using 50 samples of 20 beads. The percentage of alginate on the beads $[5.6 \%(\mathrm{w} / \mathrm{v})]$ was calculated making a material balance, after measuring the volume of beads obtained from a defined volume of sodium alginate solution. The solids content of the alginate beads $[6.2 \%(\mathrm{w} / \mathrm{w})]$ was obtained by drying at $105^{\circ} \mathrm{C}$ until constant weight. 


\section{Equilibrium experiments}

Solutions of $\mathrm{Cr}\left(\mathrm{NO}_{3}\right)_{3}$ in $0.01 \mathrm{M}$ aqueous solution of $\mathrm{NaNO}_{3}$ with chromium concentrations varying from $0.0001 \mathrm{M}$ to $0.08 \mathrm{M}$ were prepared in volumetric flasks. Aliquots of $100 \mathrm{ml}$ of these solutions were transferred to $250 \mathrm{ml}$ screw-capped polyethylene Erlenmeyer's flasks. The pH of the solutions was measured.

Aliquots $(9.30 \mathrm{~g})$ of calcium alginate beads ( $1000 \pm 3$ beads) were weighed and added to the chromium (III) solutions to obtain 10 beads per $\mathrm{ml}$ of chromium solution.

The flasks were closed and shaked on the orbital shaker at $200 \mathrm{rpm}$ and at temperatures between 10 and $27^{\circ} \mathrm{C}$.

The experiments were concluded after 8 hours: it was experimentally determined that at the end of this period equilibrium had been achieved. Final $\mathrm{pH}$ was measured (at the temperature of $27^{\circ} \mathrm{C}$ ).

Samples of the treated solution were removed, diluted, acidified with $\mathrm{HNO}_{3}$ to a $\mathrm{pH}$ of below 2, and kept at $4^{\circ} \mathrm{C}$ for subsequent analysis. Chromium was determined by atomic absorption spectroscopy and calcium by flame emission spectroscopy.

\section{Kinetics experiments}

Solutions of $\mathrm{Cr}\left(\mathrm{NO}_{3}\right)_{3}$ in $0.01 \mathrm{M} \mathrm{NaNO}_{3}$ aqueous solution with chromium (III) concentrations from $0.0001 \mathrm{M}\left(5.2 \mathrm{mg} \mathrm{Cr}^{-1}\right)$ to $0.02 \mathrm{M}\left(1040 \mathrm{mg} \mathrm{Cr}^{-1}\right)$ were prepared in volumetric flasks. Aliquots of $250 \mathrm{Ml}$ of these solutions were transferred to 500-ml screw-capped polyethylene Erlenmeyer's flasks.

Aliquots $(23.25 \mathrm{~g})$ of calcium alginate beads ( $2500 \pm 10$ beads) were weighed, to obtain 10 beads per $\mathrm{ml}$ of chromium solution (corresponding to $5.2 \mathrm{~g}^{-1}$ dry alginate). The flasks and the alginate beads (separately) were placed inside an incubator to achieve the desired temperature. After thermal equilibrium, the alginate beads were added to the chromium (III) solutions, the flasks were closed and placed immediately on the orbital shaker-incubator set at $200 \mathrm{rpm}$ at the desired temperature.

At appropriate time periods, $1 \mathrm{ml}$ samples were removed, acidified with $\mathrm{HNO}_{3}$ to $\mathrm{pH}$ below 2, diluted and kept at $4^{\circ} \mathrm{C}$. They were subsequently analysed by atomic absorption spectroscopy for chromium.

\section{Mathematical models}

To calculate the diffusion coefficients of trivalent chromium in the alginate beads, two models were used: the linear absorption model, LAM, and the shrinking core model, SCM.

It is assumed that sorption occurs from a wellstirred solution of initial solute concentration $C_{L 0}$ and finite volume $\mathrm{V}$, into a spherical particle initially without solute. In both models it is assumed that there is chemical reaction of the solute with active sites inside the sphere, but the reaction rate is much higher than the rate of diffusion in the particle, and also that there is no resistance to mass transfer in the film around the sphere. In other words, the diffusion of the solute inside the particle is considered the limiting step of the sorption process.

Figure 1 represents a scheme of the concentration profiles inside a spherical particle, according to both models cited.

\section{LINEAR ABSORPTION MODEL (LAM)}

The LAM, based on Fick's law and presented by Crank (1956), assumes that at each point inside the sphere there is a local equilibrium between the reacted and the free solute, and, for this case the equation representing the concentration in solution as a function of time is:

$$
C_{L}(t)=\frac{\alpha C_{L 0}}{1+\alpha}=6 \alpha C_{L 0} \sum_{n=1}^{\infty} \frac{\exp \left[-D_{e} q_{n}^{2} t /\left(R^{2} K_{p}\right)\right]}{9+9 \alpha+q_{n}^{2} \alpha^{2}}
$$

where $\mathrm{q}_{\mathrm{n}}$ arc the positive roots of the equation:

$$
\tan q_{n}=\frac{3 q_{n}}{3+\alpha q_{n}^{2}}
$$

$\alpha$ is defined by:

$$
\alpha=\frac{\mathrm{C}_{\mathrm{L} \omega}}{\mathrm{C}_{\mathrm{L} 0}-\mathrm{C}_{\mathrm{L} \infty}}
$$

where $K_{p}$ is the partition coefficient between the solid and liquid phase, equal to $(K+1)$, and $K$ the equilibrium ratio between the immobilised and the diffusing substance.

\section{SHRINKING CORE MODEL (SCM)}

The SCM, applied by Levenspiel (1972) to fluid particle chemical reactions, and more specifically to ionic exchange of heavy metals by Rao \& Gupta (1982), assumes that the diffusion through a reacted shell is the limiting step, and that an 


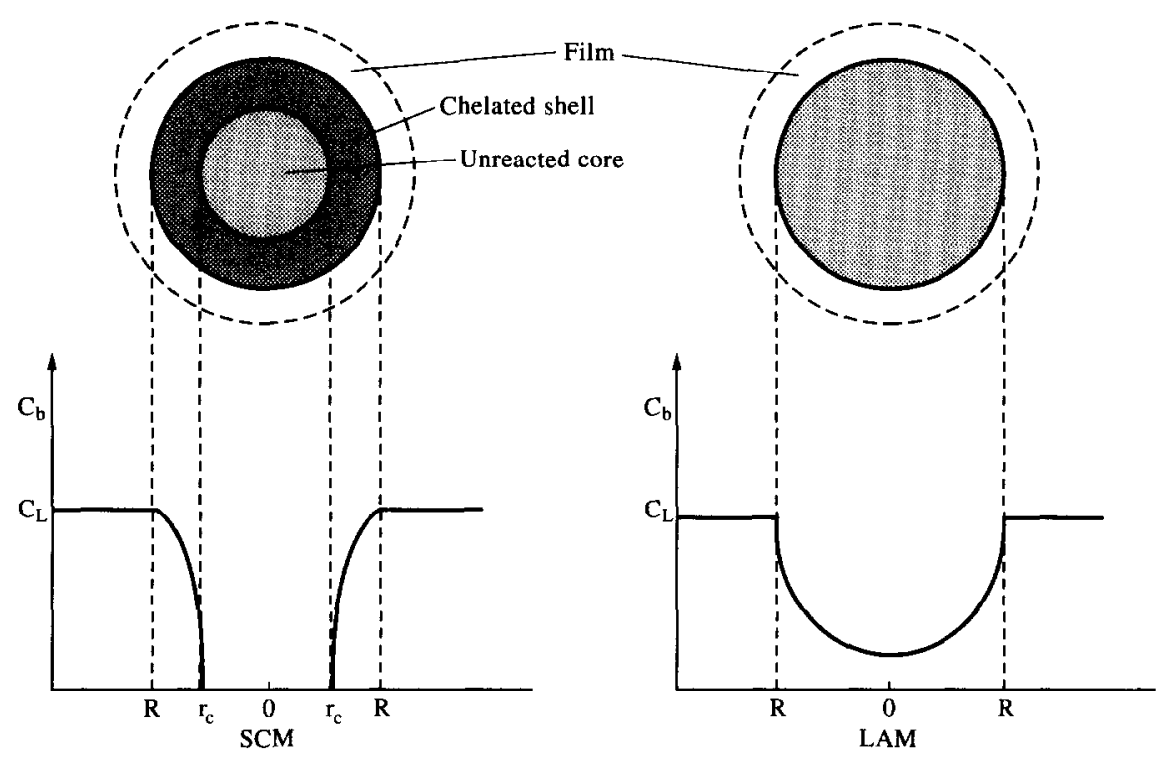

Fig. 1. Scheme of the concentration profile inside a sphere, according to both models, SCM and LAM, considering the diffusion in the sphere of the limiting step (adapted from Levenspiel, 1972).

unreacted core is shrinking as time proceeds. The final equation is:

$$
\left[1-3(1-X)^{2 / 3}+2(1-X)\right]=\frac{6 D_{e}}{c^{0} R^{2}} \int_{0}^{t} C_{L} d t
$$

Calling $F(X)$ to the function:

$$
F(X)=\left[1-3(1-X)^{2 / 3}+2(1-X)\right]
$$

then a plot of $F(X)$ versus $\int_{0}^{t} C_{L} d t$ will give a straight fine of slope $\left(6 D_{e}\right) /\left(C^{0} R^{2}\right)$, where the diffusion coefficient of the metal on the particle can be obtained.

Jang et al. (1991 and Jang, 1994), Chen et al. (1993), and Lewandowski \& Roe (1994), applied this model to calculate the diffusion coefficient of copper $\left(\mathrm{Cu}^{2+}\right)$ on calcium alginate beads, having considered $\mathrm{C}^{0}$ as the average binding site density of the spheres, defined by:

$$
\mathrm{C}^{0}=\frac{\left(\mathrm{C}_{\mathrm{L} 0}-\mathrm{C}_{\mathrm{L} \infty}\right) \mathrm{V}}{\mathrm{n} \frac{4}{3} \pi \mathrm{R}^{3}}
$$

and calculated $\mathrm{X}$ from the equation:

$$
X(t)=\frac{\left[C_{L 0}-C_{L}(t)\right]}{\left[C_{L 0}-C_{L \infty}\right]}
$$

\section{RESULTS AND DISCUSSION}

\section{Equilibrium results}

\section{Equilibrium isotherms}

The relationship obtained between chromium concentrations in the alginate beads and in the solution at equilibrium (isotherms), is shown in Fig. 2 for two temperatures. According to Brunauer classification (Figueiredo, 1981), the isotherms are of type IV, for they have an inflexion point and a maximum concentration on the beads.

Figure 2 shows that at the temperature of $27^{\circ} \mathrm{C}$, the capacity of the alginate beads to remove chromium is higher than at $10^{\circ} \mathrm{C}$. The difference increases as the concentration on the beads reaches the saturation value. At $27^{\circ} \mathrm{C}$, the saturation concentration of the beads at $27^{\circ} \mathrm{C}$ is $0.15 \mathrm{mmol}^{\mathrm{ch}}$ chomium $\mathrm{g}^{-1}$, which is a value $50 \%$ higher than saturation concentration at $10^{\circ} \mathrm{C}$ $\left(0.10 \mathrm{mmol}^{\mathrm{ch}}\right.$ romium $\left.\mathrm{g}^{-1}\right)$.

Furthermore, the isotherms at $27^{\circ} \mathrm{C}$ show an inflexion point at chromium concentrations on the solution of about $10 \mathrm{mmoll}^{-1}$, and chromium concentrations on the beads of $0.065 \mathrm{mmol} \mathrm{g}^{-1}$ $\left(3.4 \mathrm{mg} \mathrm{g}^{-1}\right)$ and at $10^{\circ} \mathrm{C}$ of $0.055 \mathrm{mmol} \mathrm{g}^{-1}$ $\left(2.9 \mathrm{mg} \mathrm{g}^{-1}\right)$. These inflexion points indicate that there are at least two different mechanisms of chromium sorption.

Figure 3 shows the amount of calcium released from the alginate beads $\mathrm{MCa}$ (expressed in $\mathrm{mmol} \mathrm{Ca}^{-1}$ beads) as a function of the amount of chromium sorbed. This plot confirms that there is more than one mechanism of sorption.

At chromium concentrations below the inflexion point on the isotherms $\left(\sim 0.06 \mathrm{mmol} \mathrm{g}^{-1}\right)$, the chromium sorbed is accompanied by calcium release, with a ratio of $1.3 \mathrm{~mol} \mathrm{Ca}{ }^{2+} \mathrm{mol}^{-1} \mathrm{Cr}^{3+}$. 


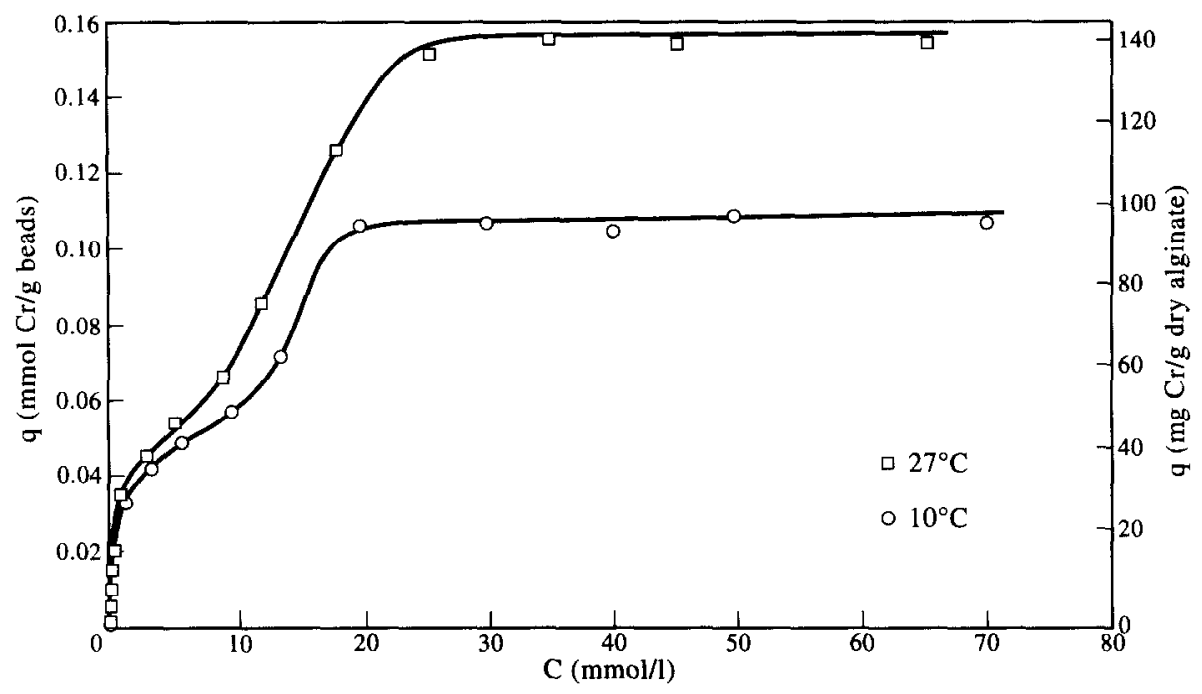

Fig. 2. Equilibrium isotherms: chromium concentration in the beads (q) as a function of chromium concentration in the solution (C), at equilibrium, at two temperatures, using $5.2 \mathrm{~g}$ dry alginate/litre of solution $(93 \mathrm{~g}$ beads $/ 1)$.

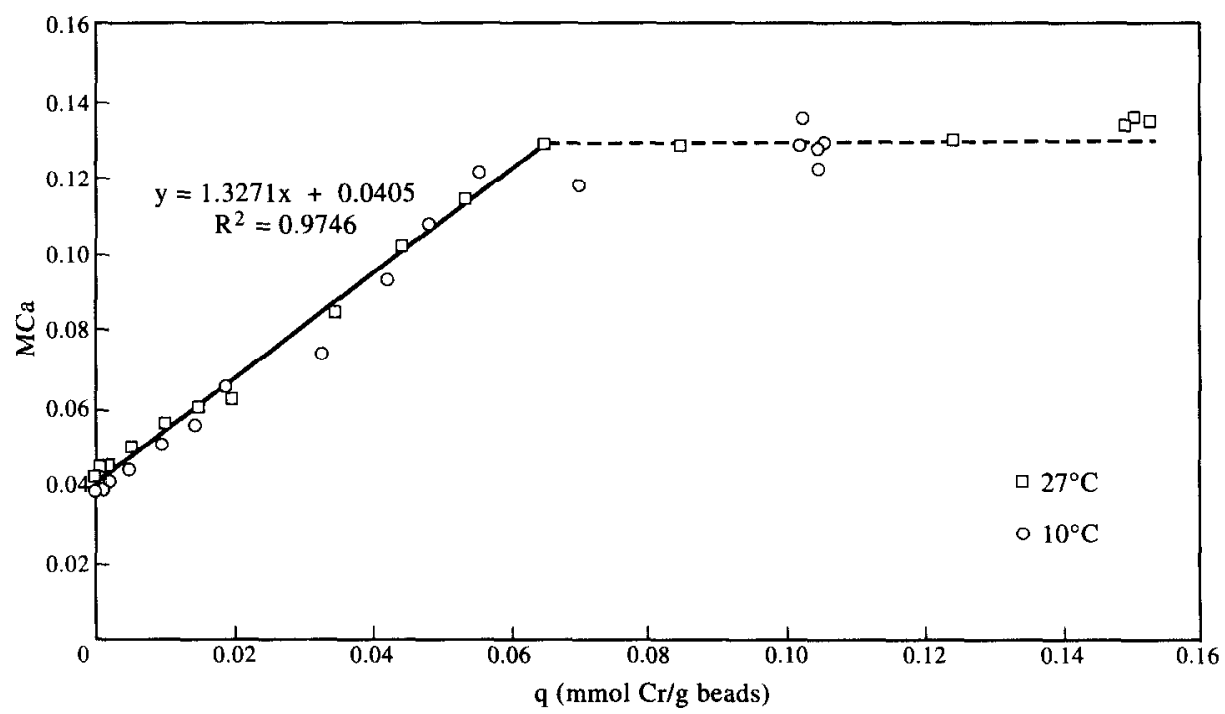

Fig. 3. Amount of calcium released from the alginate beads as a function of the amount of chromium sorbed, at equilibrium.

This slope lies between the stoichiometric ratio for $\mathrm{Ca}^{2+} / \mathrm{Cr}^{3+}$ (1.5) and $\mathrm{Ca}^{2+} / \mathrm{CrOH}^{2+}$. Since at the working $\mathrm{pH}$ range (2.5-4), both of these species $\left(\mathrm{Cr}^{3+}\right.$ and $\left.\mathrm{CrOH}^{2+}\right)$ coexist in equilibrium (Leyva-Ramos et al., 1995), we can then postulate that at low and medium chromium concentrations (below $10 \mathrm{mmol} \mathrm{Cr}(\mathrm{III}) / 1^{-1}$ ), the ionic exchange is the predominant sorption mechanism. For higher concentrations of chromium, other mechanisms of sorption occur, for there is no further release of calcium as the amount of chromium sorbed by the alginate increases.

The maximum chromium sorption achieved by the alginate beads was $0.14 \mathrm{~g} \mathrm{Cr} \mathrm{g}^{-1}$ dry alginate at $27^{\circ} \mathrm{C}$ and $0.10 \mathrm{~g} \mathrm{Crg}^{-1}$ dry alginate at $10^{\circ} \mathrm{C}$. In comparison, Jang et al., 1991, obtained for copper sorption, a value of $0.09 \mathrm{~g} \mathrm{Cu} \mathrm{g}^{-1}$ dry alginate.

\section{EFFECT OF ALGINATE AMOUNT ON EQUILIBRIUM RESULTS}

The relations between the amount of alginate beads (expressed as beads dry weight) and the chromium removal $\left[\left(\mathrm{C}_{\mathrm{L} \infty}-\mathrm{C}_{\mathrm{L} 0}\right) / \mathrm{C}_{\mathrm{L} 0}\right]$, was studied at two initial chromium concentrations ( 8 and $20 \mathrm{mmoll}^{-1}$ at $10^{\circ} \mathrm{C}$. The results are presented in Fig. 4. Although a more efficient removal is obtained for higher alginate concentrations, as expected, results suggest the existence of transport limitations when more alginate is used. 


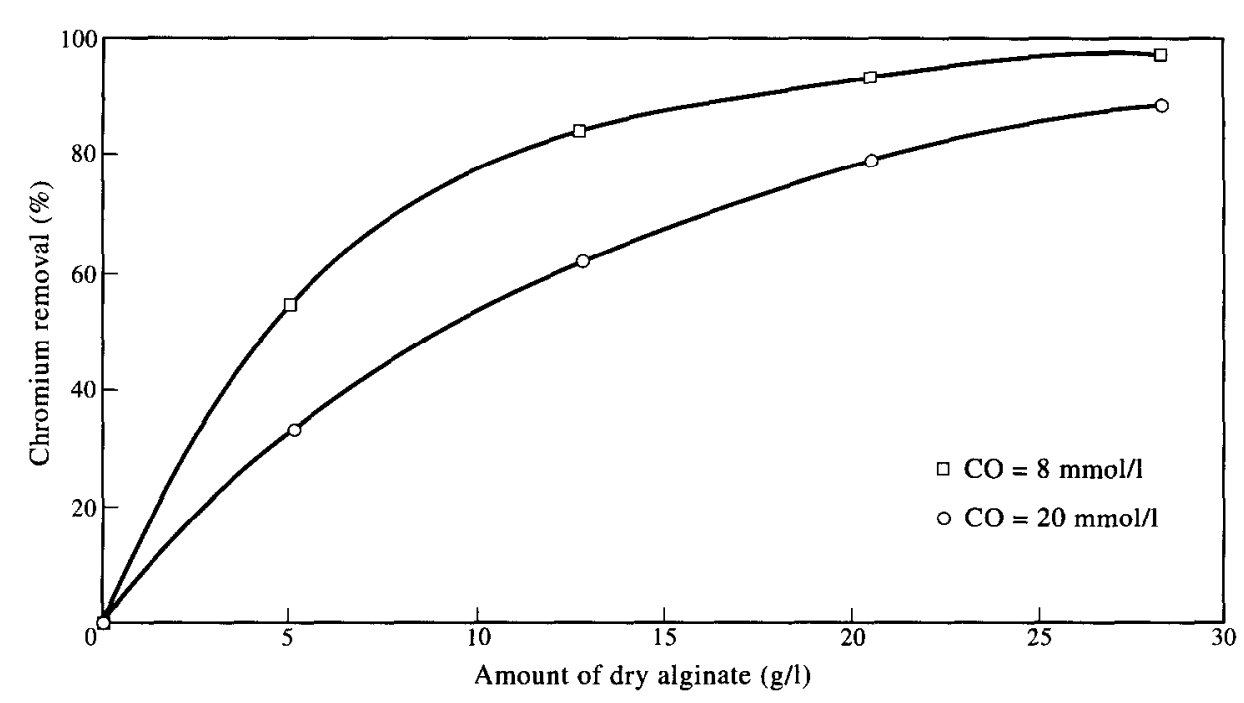

Fig. 4. Efficiency of chromium removal by the calcium alginate beads, as a function of amount of dry alginate for two initial chromium concentrations.

\section{EFFECT OF PH ON EQUILIBRIUM RESULTS}

Figure 5 represents the chromium sorption by the alginate beads at different initial $\mathrm{pH}$ values for $0.02 \mathrm{M} \mathrm{Cr}\left(\mathrm{NO}_{3}\right)_{3}$ solutions. As the plot shows, in the range studied $(\mathrm{pH} 2-4)$, higher $\mathrm{pH}$ values resulted in higher chromium sorption.

According to the speciation diagram for $\mathrm{Cr}(\mathrm{III})$ complexes in aqueous solutions, from LeyvaRamos et al. (1995), at $\mathrm{pH} 2$ the molar percentage of $\mathrm{Cr}^{3+}$ is $98 \%$ of the total amount of chromium in solution, while at $\mathrm{pH} 4$, this value decreases to about $40 \%$ and almost $60 \%$ is in the ionic form $\mathrm{CrOH}^{2+}$ (and a trace amount of $\mathrm{Cr}(\mathrm{OH})_{4}{ }^{5+}$ ).

The stoichiometric relationship for the ionic exchange between calcium and chromium occurring on the alginate beads, is of $1.5: 1$ for $\mathrm{Ca}^{2+}$ to $\mathrm{Cr}^{3+}$, and $1: 1$ for $\mathrm{Ca}^{2+}$ to $\mathrm{CrOH}^{2+}$. To a specific amount of $\mathrm{Ca}^{2+}$ ions available to ionic exchange in the alginate, the same amount of $\mathrm{CrOH}^{2+}$ ions can be removed, while only $67 \%(1 / 1.5)$ of that amount of $\mathrm{Cr}^{3+}$ ions can be exchanged. This is probably the major reason, because at $\mathrm{pH} 4$ where about $60 \%$ of the chromium is in the ionic form of $\mathrm{CrOH}^{2+}$, the chromium sorption is higher than at $\mathrm{pH} \mathrm{2,}$ where almost all the chromium is in the ionic form $\mathrm{Cr}^{3+}$. However, theoretically, at $\mathrm{pH} 4$, the chromium removal should have increased by $15 \%$. The experimental increase was $23 \%$, which suggests that some other factors might account for this difference. For example, alginate might have different affinities to the different species of chromium existing in the solution, or its affinity towards chromate might be affected by its interactions with other ions. Also, at lower $\mathrm{pH}$, there is a smaller amount of carboxylic groups available for gel formation and consequently the ionic exchange process might be reduced.

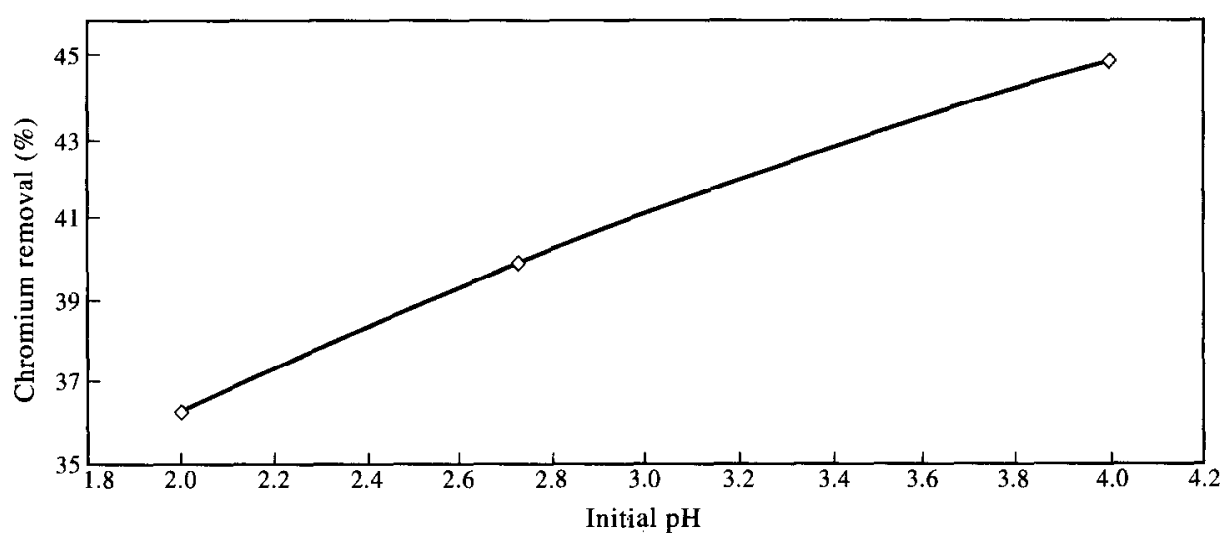

Fig. 5. Effect of initial $\mathrm{pH}$ on chromium removal by the calcium alginate beads, for an initial concentration of $20 \mathrm{mmol} / 1$, at $27^{\circ} \mathrm{C}$. 


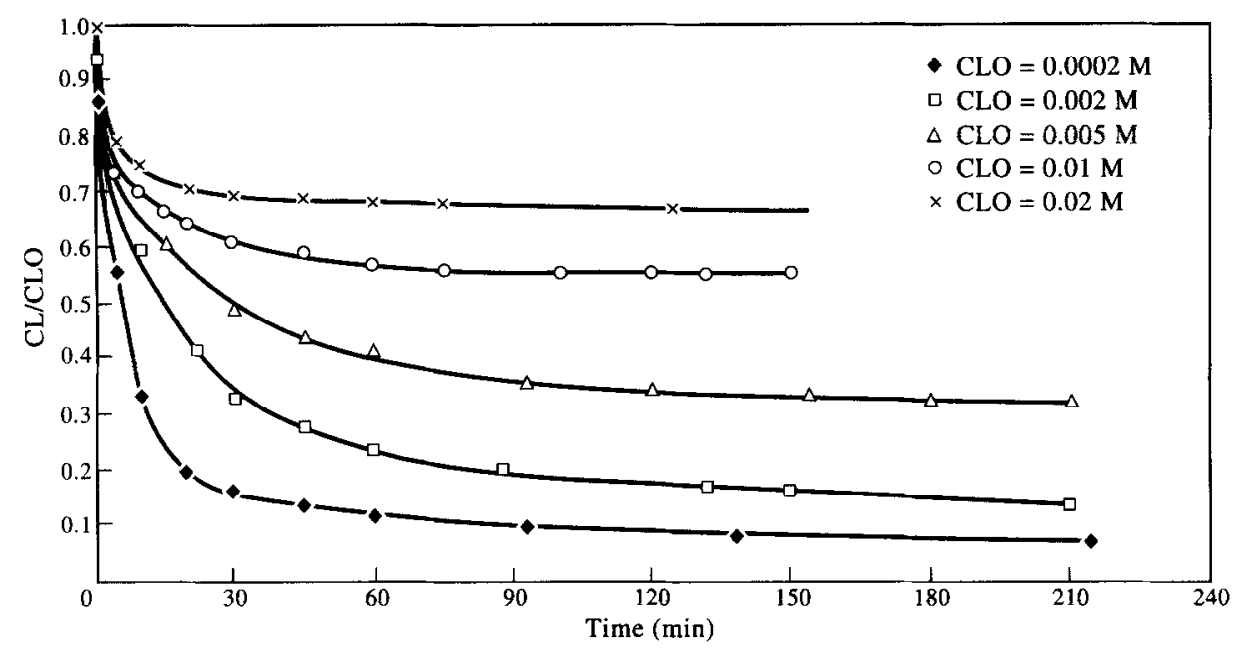

Fig. 6. Normalised chromium concentration $\left(C_{L} / C_{L 0}\right)$ as a function of time, at different initial chromium concentrations $\left(C_{L 0}\right)$, at $10^{\circ} \mathrm{C}$, using $5.2 \mathrm{~g}$ dry alginate per litre of chromium solution.

\section{Kinetics experiments}

Some of the experiments made at different initial chromium concentrations $\left(\mathrm{C}_{\mathrm{L} 0}\right)$ are represented in Fig. 6. This figure shows the normalised concentration $\left(\mathrm{C}_{\mathrm{L}} / \mathrm{C}_{\mathrm{L} 0}\right)$ as a function of time at $10^{\circ} \mathrm{C}$.

Using these and other experiments, an attempt was made to fit the sorption rate Eq. (8) to the experimental results:

$$
-\mathrm{dC}_{\mathrm{L}} / \mathrm{dt}=\mathrm{kC}_{\mathrm{L}}^{\mathrm{a}}
$$

where $-\mathrm{dC}_{\mathrm{L}} / \mathrm{dt}$ is the rate of chromium sorption by the alginate beads, $a$ is the reaction order relative to chromium concentration, and $k$ is the rate constant (Levenspiel, 1972). Since the alginate concentration was the same in all experiments, these parameters were calculated by the initial rate method (during the first 5 minutes $\left\{-\mathrm{dC}_{\mathrm{L}} /\right.$ $\left.\left.\left.\mathrm{dt}=\left[\mathrm{C}_{\mathrm{L} 0}-\mathrm{C}_{\mathrm{L} 0}=5 \mathrm{~min}\right)\right] /(5 \times 60)\right\}\right)$. These results are plotted in Fig. 7.

The rate equation then obtained, with respect to chromium concentration on the solution $\left(\mathrm{C}_{\mathrm{L}}\right)$ was:

$$
\left.-\mathrm{dC}_{\mathrm{L}} / \mathrm{dt}\left[\mathrm{mmol1}^{-1} \mathrm{~s}^{-1}\right)\right]=0.00115 \mathrm{C}_{\mathrm{L}}^{0.84}
$$

\section{Determination of diffusion coefficients}

The diffusion coefficients were calculated by the LAM and SCM models (briefly described on the section Materials and methods) and are plotted in Fig. 8, as a function of initial chromium concentration at $10^{\circ} \mathrm{C}$.

To calculate $D_{e}(L A M)$, the best fit to Eq. (1)

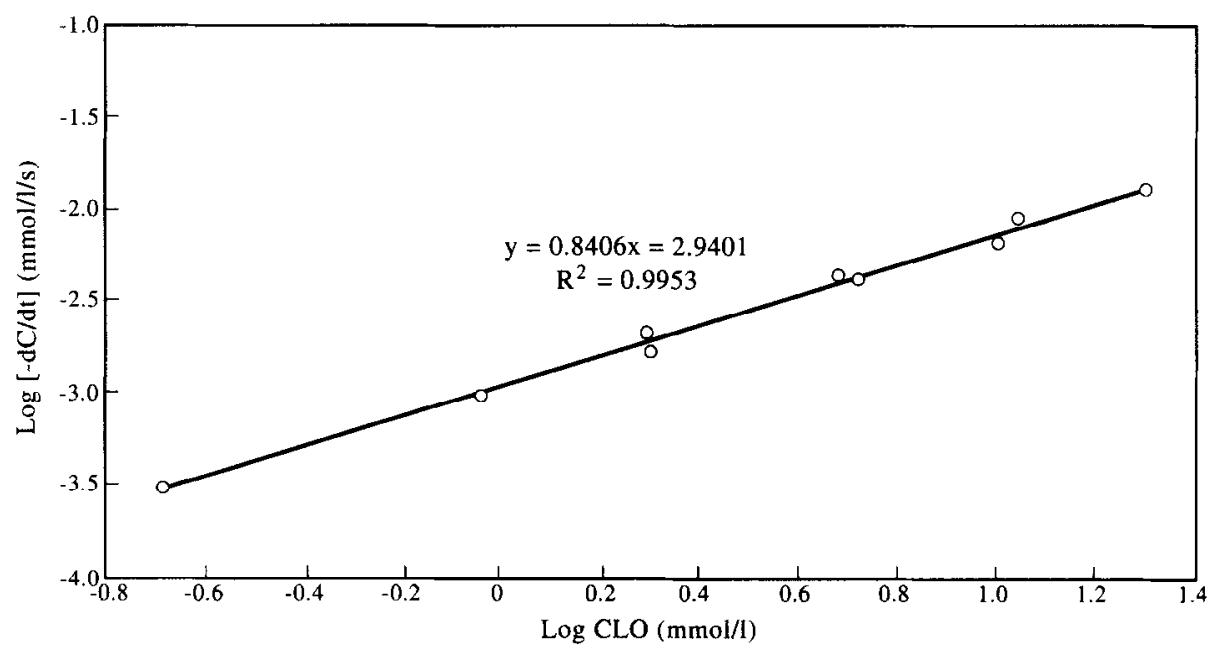

Fig. 7.Logarithm of the initial rate of chromium sorption as a function of the logarithm of initial chromium concentration in solution, at $10^{\circ} \mathrm{C}$, using $5.2 \mathrm{~g}$ dry alginate per litre of chromium solution. 


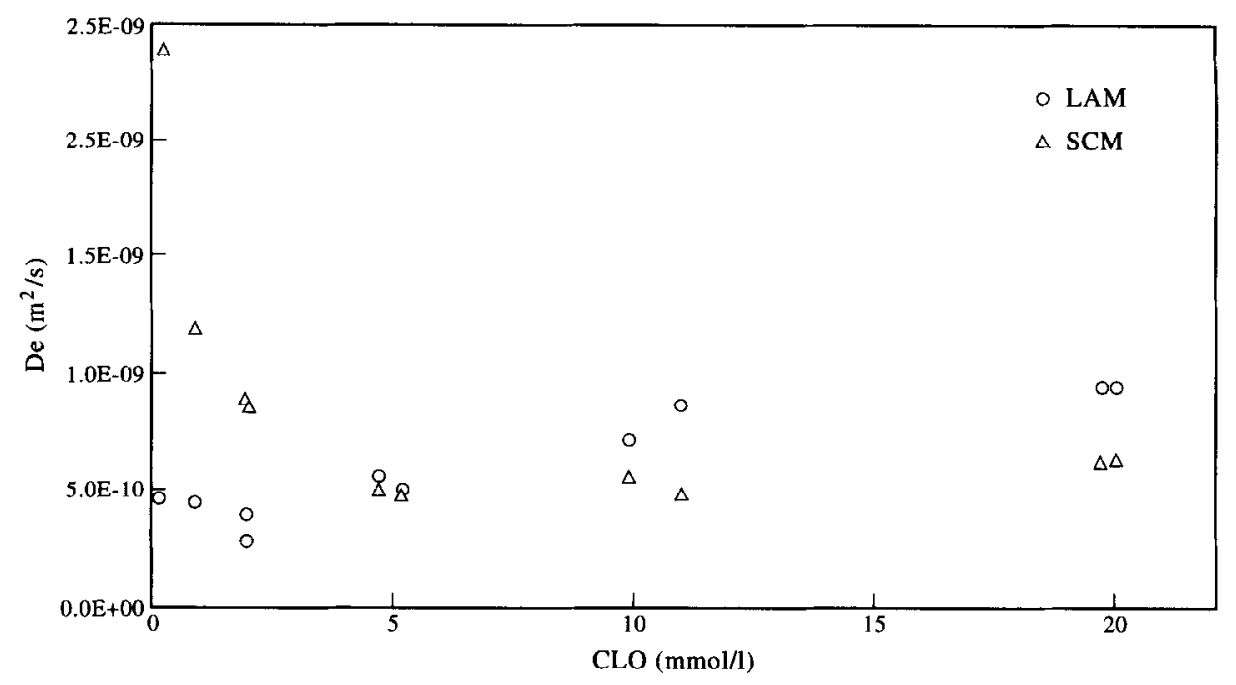

Fig. 8.Diffusion coefficients of chromium in alginate beads, as a function of the initial chromium concentration in solution, calculated by the two different models (LAM and SCM). The experiment was set at $10^{\circ} \mathrm{C}$, with 10 alginate beads/ml $(5.2 \mathrm{~g}$ dry alginate per litre of chromium solution).

was determined, having the number of terms of the sum been limited to 200 .

To calculate $D_{e}(S C M)$, a plot of $F(X)$ versus $\int_{0}^{t} C_{L} d t$ was made. For the lower values of $\int_{0}^{t} C_{L} d t$ the results were fitted to a straight line, and by multiplying the corresponding slope by $\left(\mathrm{C}_{\mathrm{L} 0} * \mathrm{R}^{2}\right)$ 6), $D_{e}(S C M)$ is obtained. The values of $\int_{0}^{t} C_{L} d t w e r e$ calculated by integration of $C_{L}(t)$ by the trapezoid rule.

The analysis of the correlation coefficients obtained after fitting the experimental data to LAM and SCM models allowed us to conclude that LAM describes better the diffusion process for larger chromium concentrations, while for the smaller concentrations SCM is the best model. This can be explained by the fact that at low concentration the ionic exchange is the governing mechanism, while at higher concentration this mechanism does not prevail.

Figure 8 presents a plot of the diffusion coefficients calculated by the two models, LAM and SCM, as a function of initial chromium concentration in the solution at $10^{\circ} \mathrm{C}$. The analysis of this figure indicates that:

diffusion coefficients obtained by SCM model are much more dependent on chromium concentration than those obtained by LAM model at low chromium concentration (below $\left.2 \mathrm{mmoll}^{-1}\right), \mathrm{D}_{\mathrm{e}}(\mathrm{LAM})$ and $\mathrm{D}_{\mathrm{e}}(\mathrm{SCM})$ are quite different, with $\mathrm{D}_{\mathrm{e}}(\mathrm{SCM})$ being superior to $\mathrm{D}_{\mathrm{e}}$ (LAM). In this region, $\mathrm{D}_{\mathrm{e}}(\mathrm{SCM})$ decreases almost exponentially with the increase of chromium concentration (from
$2.39 \times 10^{-9} \mathrm{~m}^{2} \mathrm{~s}^{-1}$ for $\mathrm{C}_{\mathrm{LO}}=0.2 \mathrm{mmoll}^{-1}$ until $5.01 \times 10^{-10} \mathrm{~m}^{2} \mathrm{~s}^{-1}$ for $\mathrm{C}_{\mathrm{L} 0}=2 \mathrm{mmoll}^{-1}$ ), while $D_{e}(L A M)$ just reduces slightly (from $4.70 \times 10^{-10} \mathrm{~m}^{2} \mathrm{~s}^{-1}$ for $\mathrm{C}_{\mathrm{L} 0}=0.2 \mathrm{mmoll}^{-1}$ until about $3 \times 10^{-10} \mathrm{~m}^{2} \mathrm{~s}^{-1}$ for $\mathrm{C}_{\mathrm{L} 0}=2 \mathrm{mmol}^{-1}$ ). at higher chromium concentration (above $\left.10 \mathrm{mmoll}^{-1}\right), \mathrm{D}_{\mathrm{e}}(\mathrm{SCM})$ is inferior to $\mathrm{D}_{\mathrm{e}}(\mathrm{LAM})$, but the difference does not seem to increase as the chromium concentration becomes larger.

the results obtained for $D_{e}(S C M)$ and $\mathrm{D}_{\mathrm{e}}$ (LAM) are not very different in the region of initial chromium concentration of about $5 \mathrm{mmoll}^{-1}$.

Jang et al. (1991) applied the SCM to diffusion of $\mathrm{Cu}^{2+}$ in alginate gels, having concluded that this model describes satisfactorily the process, except for periods toward the end of absorption.Chen et al. (1993) applied both models, LAM and SCM, to the diffusion of $\mathrm{Cu}^{2+}$ in calcium alginate beads, having concluded that LAM is preferable to the SCM for this system, because with LAM a dependence of the diffusion coefficient on alginate concentration on the beads was obtained. Using the data of Chen et al. (1993) a recalculation of the diffusion coefficients was made by Lewandowski \& Roe (1994). It was confirmed that the diffusivity increases with increasing alginate concentration, but at a lower rate than reported by Chen $e t$ al. (1993). For experiments with initial concentration of $1 \mathrm{mmoll}^{-1} \mathrm{CuCl}_{2}$, at $25^{\circ} \mathrm{C}$, the diffusivity of $\mathrm{Cu}^{2+}$ in alginate beads (with $3 \%$ of alginate) was $0.98 \times 10^{-9} \mathrm{~m}^{2} \mathrm{~s}^{-1}$, for the SCM, and $1.08 \times 10^{-9} \mathrm{~m}^{2} \mathrm{~s}^{-1}$ for LAM.In all our experiments, 
a constant alginate concentration $(3 \%)$ in the beads, was used for different initial chromium concentrations. The temperature was $10^{\circ} \mathrm{C}$, and the anion used was nitrate. This was used because of problems arising from the use of chloride, since this anion forms complexes with chromium. The calculated diffusion coefficients for the experiment (chromium initial concentration of $0.90 \mathrm{mmoll}^{-1}$ ) presenting the closest experimental conditions to those of Chen et al. (1993) were $1.20 \times 10^{-9} \mathrm{~m}^{2} \mathrm{~s}^{-1}$ (SCM) and $4.51 \times 10^{-10} \mathrm{~m}^{2} \mathrm{~s}^{-1}$ (LAM). Although, it is not adequate to compare values with different experimental conditions, it may be seen that they are of the same order of magnitude of those obtained for copper ions. The variation of chromium diffusion coefficients with chromium concentration may be explained, as Tyrrel \& Harris (1984) pointed out, by the fact that the diffusion coefficients of electrolytes change with concentration in ways that are difficult to predict. In their work involving aqueous halides, as concentration increased, there was an initial rapid fall on diffusion coefficients leading to a minimum value, followed by an increase. This is the type of behaviour obtained in this work for $\mathrm{D}_{\mathrm{e}}(\mathrm{SCM})$.

\section{EFFECT OF TEMPERATURE}

The influence of temperature was studied for the initial concentration of $20 \mathrm{mmoll}^{-1}$ chromium, using $5.2 \mathrm{~g}$ dry alginate $\mathrm{l}^{-1}$ (10 beads per $\mathrm{ml}$ ). The results obtained are shown in Fig. 9.

Figure 10 presents the Arrhenius plot for chromium diffusion coefficients determined by
LAM and SCM models. The activation energy of the diffusion process $\left(E_{a}\right)$, was obtained considering $\mathrm{D}_{\mathrm{e}}$ proportional to $\mathrm{e}^{-\mathrm{Ea} / \mathrm{RT})}$. The values obtained were $32.9 \mathrm{~kJ} \mathrm{~mol}^{-1}$, using $\mathrm{D}_{\mathrm{e}}(\mathrm{LAM})$, and $52.1 \mathrm{~kJ} \mathrm{~mol}^{-1}$, using $\mathrm{D}_{\mathrm{e}}(\mathrm{SCM})$. Using the SCM, the fit to Arrhenius equation was much better.

\section{Chromium removal by manufacture of chromium alginate beads}

The removal of chromium from concentrated solutions of $\mathrm{Cr}\left(\mathrm{NO}_{3}\right)_{3}$ by dropping the sodium alginate solution directly on the chromium solution, was studied. Figure 11 represents the chromium concentration in a stirred solution as a function of the amount of sodium alginate solution added.

It was verified that this method is applicable for chromium concentration above $400 \mathrm{mg} \mathrm{Crl}^{-1}$. At lower concentrations, there is no significant formation of beads.

During this experiment, the $\mathrm{pH}$ of the solution changed from an initial value of 2.95 to 3.45 when chromium concentration on the solution was

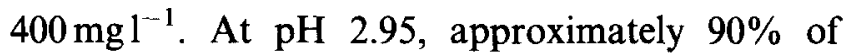
chromium is in the trivalent form while at $\mathrm{pH} 3.45$ the proportion of trivalent chromium is $75 \%$, the remaining being present as $\mathrm{CrOH}^{2+}$. This indicates that the main mechanism for chromium alginate gel formation involves the interaction between the carboxylic groups of alginic acid and the trivalent form of the chromium ion, since this is the ionic form that predominates during all the experiment.

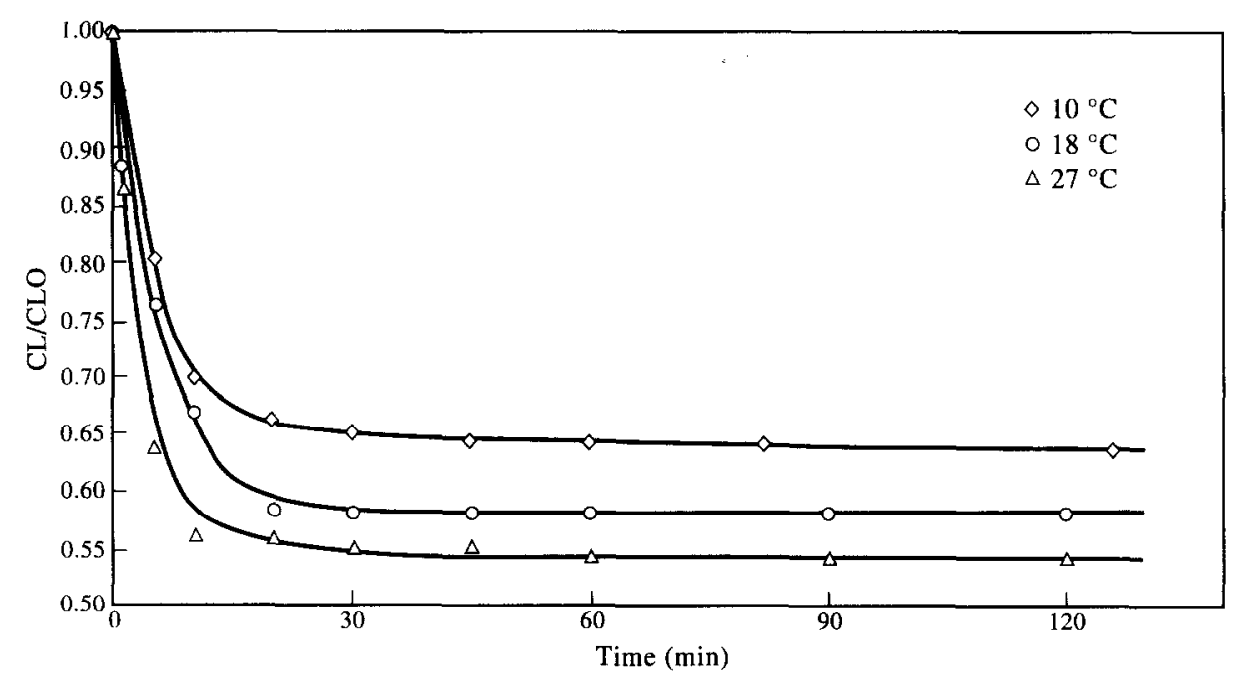

Fig. 9. Normalised chromium concentration $\left(C_{L} / C_{L 0}\right)$ as a function of time, at different temperatures, for $20 \mathrm{mmol} / 1$ initial chromium concentration $\left(\mathrm{C}_{\mathrm{L} 0}\right)$, using $5.2 \mathrm{~g}$ dry alginate per litre of chromium solution. 


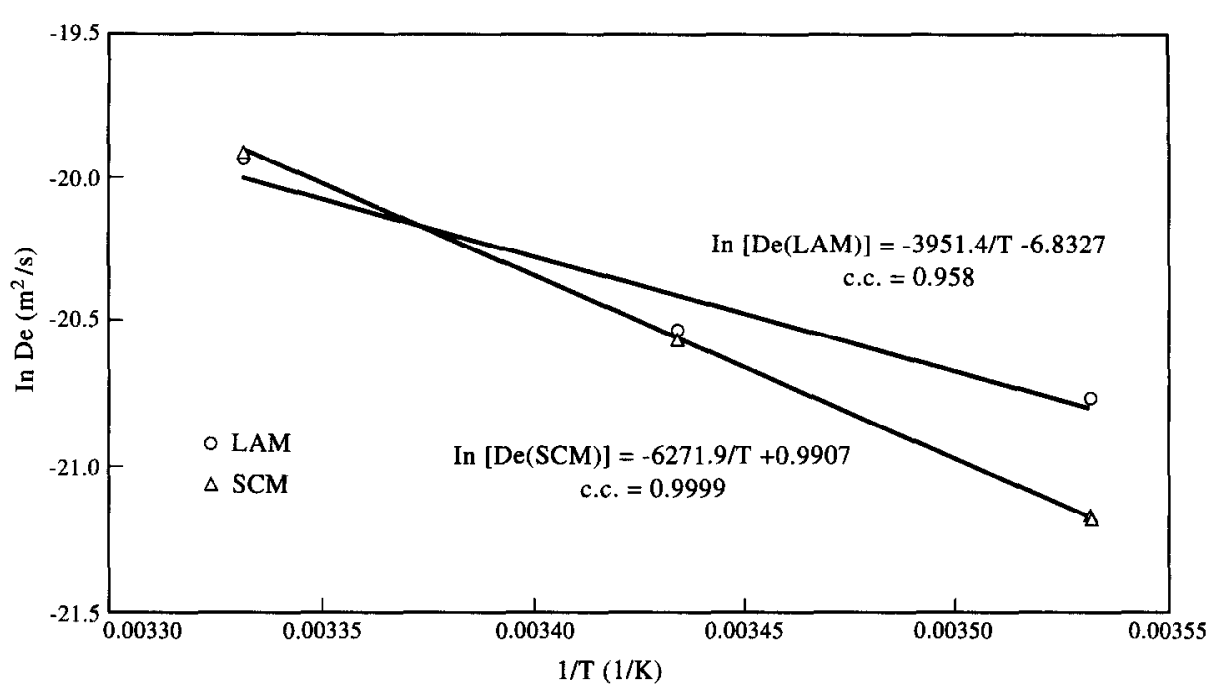

Fig. 10. Arrhenius plots, obtained using the diffusion coefficients calculated by the two models, LAM and SCM.

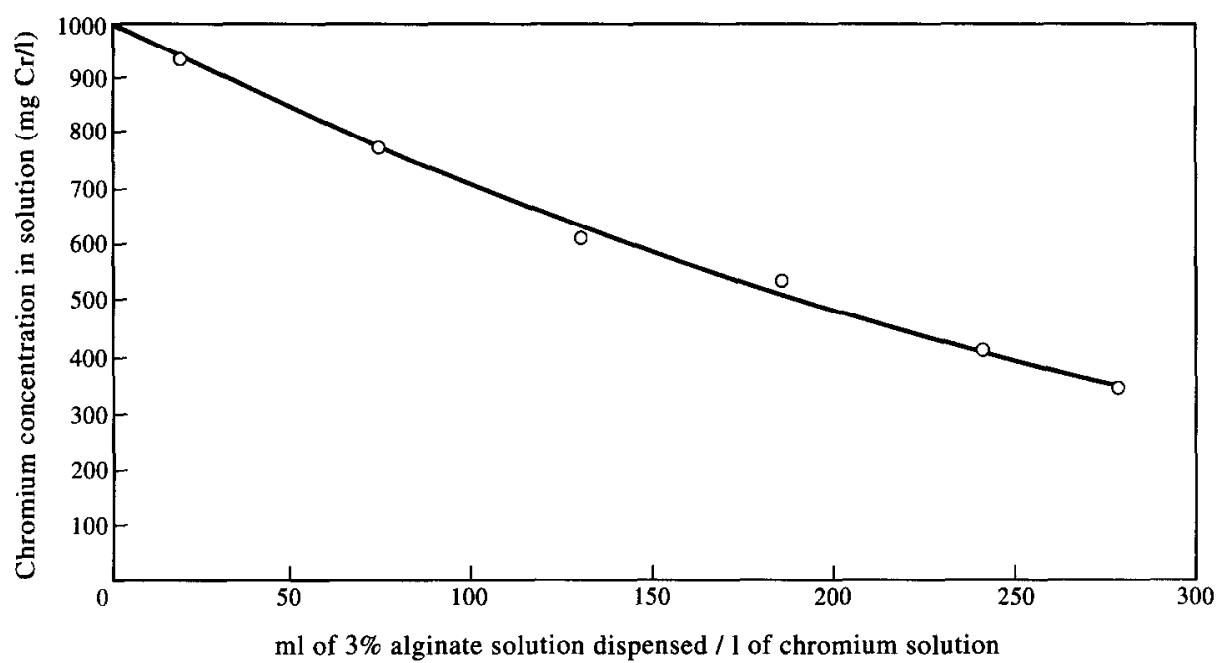

Fig. 11. Chromium concentration in solution as a function of the volume of a $3 \%$ alginate solution added to the chromium solution.

Using this process, for chromium concentrations between 400 and $1000 \mathrm{mg} \mathrm{Cr}^{-1}, 0.08 \mathrm{~g}$ of chromium can be removed per gram of dry sodium alginate $\left(2.3 \mathrm{mg} \mathrm{Crml}^{-1} 3 \%\right.$ algin solution). This procedure is similar to the one described by Jang et al. (1991) for copper, where a removal efficiency of the same order of magnitude $-0.1 \mathrm{~g} \mathrm{Cu} \mathrm{g}^{-1}$ dry alginate-was obtained.

Data indicate, that at high chromium concentration, it is more efficient to dispense sodium alginate directly in the chromium solution to remove chromium in excess of $400 \mathrm{mg} \mathrm{Cr}^{-1}$.

Figure 12 shows a possible example of a combination of this process with the process using preformed calcium alginate beads to remove chromium from an hypotetic effluent containing $1040 \mathrm{mg} \mathrm{Crl}^{-1}\left(20 \mathrm{mmoll}^{-1}\right)$, reaching a low concentration value of $1.6 \mathrm{mg} \mathrm{Cr} 1^{-1}$. The system uses three stages, the first one removes the chromium above $400 \mathrm{mg} \mathrm{Cr}^{-1}$ by dropping the alginate solution directly. The second and third stages remove the remaining chromium with calcium alginate beads. Each step is performed in stirred tanks, and the chromium contaminated alginate beads are shrunk by air drying. As can be seen in Fig. 12, the overall chromium removal efficiency is $99.8 \%$, and the volume reduction of contaminated effluent is $93.6 \%$.

\section{CONCLUSIONS}

Analysing the results obtained in this work, the following conclusions about the removal of trivalent chromium by alginate can be made: 


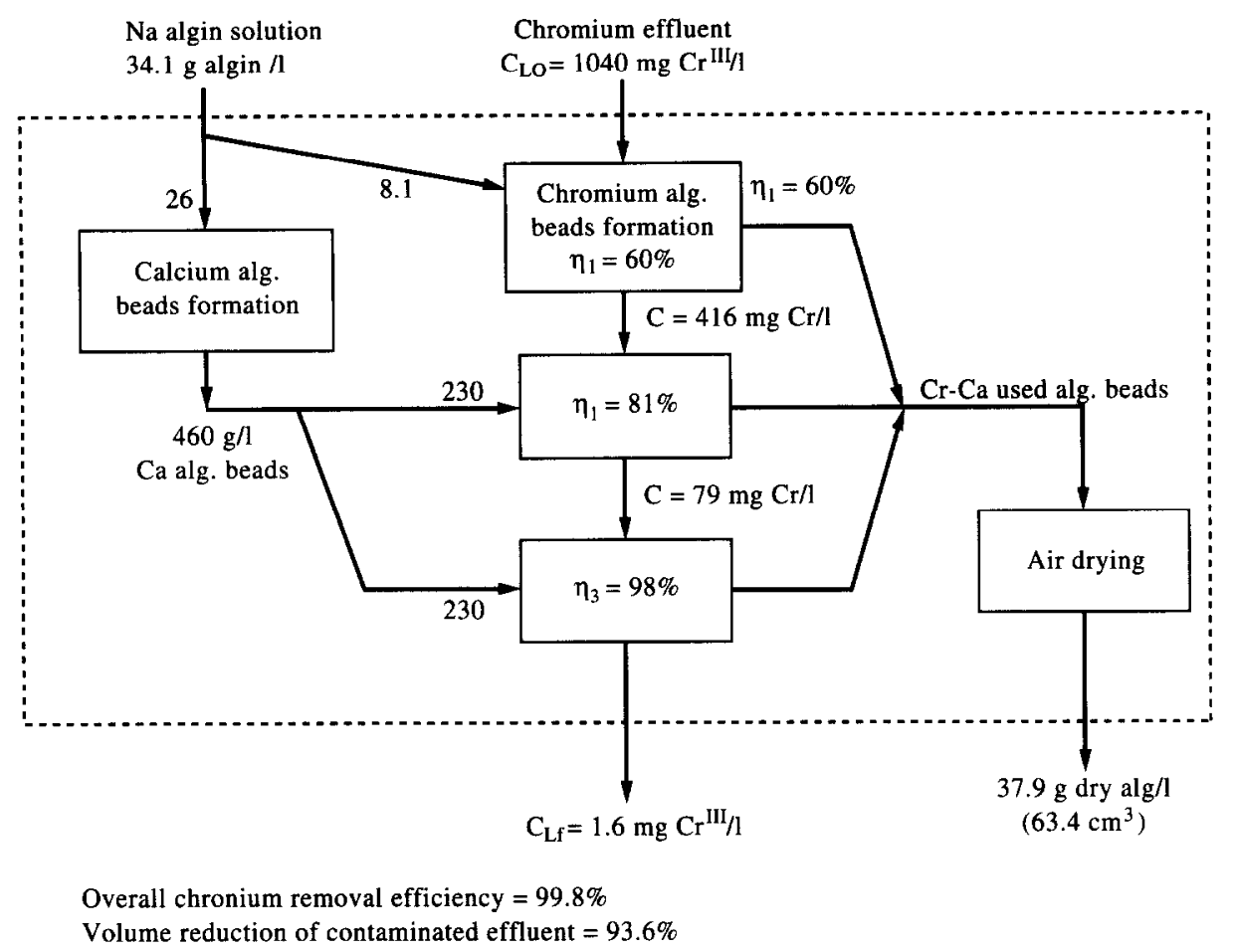

Fig. 12. Practical example of chromium removal from an effluent with initial concentration of $20 \mathrm{mmol} / 1$, using three stages: in the first stage, the chromium concentration above $400 \mathrm{mg} / 1$ is removed by directly dispensing the sodium alginate solution; the second and third stages use calcium alginate beads.

The process is efficient and offers a practical possibility to remove trivalent chromium using calcium alginate beads.

Higher temperatures (in the range of 10 to $27^{\circ} \mathrm{C}$ ) favour the sorption of chromium on calcium alginate beads, especially at chromium concentrations near the saturation of the beads. At $\mathrm{pH}$ between 2 and 4, higher values increase chromium sorption.

The sorption isotherms are of type IV according to Brunauer classification, for they contain an inflexion point and finite values of sorption capacity.

There is more than one mechanism of chromium sorption by the alginate beads. Ionic exchange with calcium appears to be the dominant process in the range of lower chromium concentrations.

The rate equation $-\mathrm{dC}_{\mathrm{L}} / \mathrm{dt}=\mathrm{kC}_{1}^{\mathrm{a}}$ describes reasonably well the kinetics of the sorption process (correlation coefficient superior to 0.995).

The Shrinking Core Model gave diffusion coefficients that were very dependent on chromium concentration, but mathematically adjusted better to the experimental results at low concentration than the Linear Absorption Model. This can be explained by the fact that at low concentrations, the ionic exchange is the governing mechanism.

The Linear Absorption Model mathematically adjusts better to the experimental results at higher chromium concentration than the Shrinking Core Model, which can be justified since in this region, the ionic exchange is no longer the main mechanism of sorption.

To remove trivalent chromium from concentrated solutions, better results can be obtained if, in a first step, the chromium above $400 \mathrm{mg}$ $\mathrm{Cr}^{-1}$ is removed by directly dispensing the alginate solution on the chromium solution, to form chromium alginate beads, and then the remaining chromium is sorbed by calcium alginate beads.

\section{REFERENCES}

Apel, M. L. \& Torma, A. E. (1993) Determination of kinetics and diffusion coefficients of metal sorption on $\mathrm{Ca}$-alginate beads. Canadian Journal of Chemical Engineering 71, 652656.

Brady, J. M. \& Tobin, J. M. (1994) Adsorption of metal ions by Rhizopus arrhizus biomass: Characterisation studies. Enzyme Microbiology Technology 16, 671-675.

Chen, D., Lewandowski, Z., Roe, F. \& Surapaneni, P. (1993) Diffusivity of $\mathrm{Cu}^{2+}$ in calcium alginate gel beads. Biotechnology and Bioengineering 41, 755-760. 
Crank, J. (1956) The Mathematics of Diffusion. Clarendon Press, Oxford.

Figueiredo, J. L. (1981) Catálise Heterogénea. CEQ/FEUP, pp. 75-79.

Holan, Z. R., Volesky, B. \& Prasetyo, I. (1993) Biosorption of cadmium by biomass of marine algae. Biotechnology and Bioengineering 41, 819-825.

Jang, L. K. (1994) Communication to the Editor: Diffusivity of $\mathrm{Cu}^{2+}$ in calcium alginate gel beads. Biotechnology and Bioengineering 43, 183-185.

Jang, L. K., Lopez, S. L., Eastman, S. L. \& Pryfogle, P. (1991) Recovery of copper and cobalt by biopolymer gels. Biotechnology and Bioengineering 37, 266-273.

Kratochvil, D., Fourest, E. \& Volesky, B. (1995) Biosorption of copper by Sargassum fluitans biomass in fixed-bed column. Biotechnology Letters 17, 777-782.

Levenspiel, O. (1972) Chemical Reaction Engineering. 2nd edn, pp. 21-32, 69-71, 357-408. John Wiley \& Sons, New York. Lewandowski, Z.\& Roe, F. (1994) Communication to the Editor:
Diffusivity of $\mathrm{Cu}^{2+}$ in calcium alginate gel beads: Recalculation. Biotechnology and Bioengineering 43, 186-187.

Leyva-Ramos, R., Fuentes-Rubio, L., Guerrero-Coronado, R. M. \& Mendoza-Barron, J. (1995) Adsorption trivalent from aqueous solutions onto activated carbon. Journal of Chemical Technology and Biotechnology 62, 64-67.

Martinsen, A., Storrø, I. \& Skjăk-Brøk, G. (1992) Alginate as immobilisation material: III. Diffusional properties. Biotechnology and Bioengineering 39, 186-194.

Rao, M. G. \& Gupta, A. K. (1982) Ion exchange processes accompanied by ionic reactions. Chemical Engineering Journal 24, 181-190.

Smidsrød, O. \& Skjåk-Brœk, G. (1990) Alginate as immobilisation matrix for cells . TIBTECH 8, 71-78.

Tyrrel, H. J. V. \& Harris, K. R. (1984) Diffusion in Liquids. A Theoretical and Experimental Study, pp. 400-402. Butterworths.

Volesky, B. (1987) Biosorbents for metal recovery. TIBTECH 5, 96-101. 